\title{
Governo Temer e contrarreforma na política de saúde: a inviabilização do SUS
}

The Temer government and counter-reforms in health policy: making the Unified Health System (SUS) unviable

\section{Raquel Cavalcante SOARES ${ }^{*}$}

\section{Introdução}

$\mathrm{D}$ ebater a atual fase da contrarreforma do Estado brasileiro é condição urgente para o desvelamento das necessidades sociais que fundam essa ofensiva contra o conjunto das conquistas da classe trabalhadora. Faremos este debate a partir de fundamentos semelhantes aos de Bravo, Pelaez e Pinheiro (2018), segundo as categorias da teoria social crítica marxiana, concebendo a unidade dialética entre política e economia. Assim, ao desenvolvermos um esforço analítico para nos apropriarmos do movimento da realidade da política de saúde brasileira no tempo atual, o faremos evidenciando e reproduzindo no pensamento as mediações entre o espaço da saúde e as necessidades do capitalismo contemporâneo, particularmente num momento de recrudescimento do autoritarismo do Estado brasileiro, configurado no que convencionou denominar de um golpe institucional (envolvendo judiciário, parlamento, grande mídia e grande empresariado), segundo Jinkings, Doria e Cleto (2016).

Os interesses do grande capital no Brasil contemporâneo, de acordo com Braz (2017), “[...] precisavam de um governo genuinamente burguês, capaz de não ceder o mínimo aos trabalhadores, de lhes retirar o pouco que conquistaram" (BRAZ, 2017, p. 87-88). A voracidade das necessidades capitalistas sobre o fundo público brasileiro evidenciam a racionalidade destrutiva do Capital na atualidade e o que Harvey (2005) denominou, a partir de Marx, de acumulação por espoliação: para além das formas primitivas de acumulação, modos contemporâneos como a propriedade intelectual sobre os recursos genéticos, a destruição e usurpação dos recursos ambientais, a corporativização e privatização de bens públicos, dentre eles, o direito à saúde.

Na atualidade, a população brasileira, particularmente a classe trabalhadora, vem enfrentando a maior ofensiva da história deste país contra o conjunto das conquistas civilizatórias de nosso Estado. Tal argumento pode ser evidenciado nas diversificadas e inúmeras medidas tomadas, desde a posse de Michel Temer: autorização para privatização de aquíferos, avanço no processo de privatização da Petrobrás, Aprovação de Reforma trabalhista, aprovação de

\footnotetext{
* Assistente Social. Doutora em Serviço Social pela Universidade Federal de Pernambuco. Professora Adjunto IV no Departamento de Serviço Social, da Universidade Federal de Pernambuco (Ufpe, Recife (PE), Brasil). Av. Prof. Moraes Rego, 1235, Cidade Universitária, Recife (PE), CEP: 50670-901. E-mail: <quelcsoares@gmail.com>. ORC ID: <http://orcid.org/oooo-0002-1276-5540>.
} 
teto de gastos por 20 anos, encaminhamento de projeto de reforma da previdência social draconiano, entre outros. Todas essas proposições levaram autores a afirmar que o conjunto de tais medidas não configuram simplesmente um programa de ajuste, mas um austericídio. Segundo Kliass (2017), os integrantes do governo Temer receberam um mandato do financismo para "[...] concluir o desmonte do Estado Brasileiro [...]" (KLIASS, 2017, não paginado), e para isso faz-se necessário acabar rapidamente com todas as barreiras dos direitos sociais presentes na Constituição. De acordo com Marques e Ugino (2017), a reforma trabalhista e a proposta de reforma da previdência, além do conjunto de medidas de liberalização do patrimônio nacional (como a venda da Eletrobrás, entrega da exploração do Pré-Sal para outras empresas que não a Petrobrás, anúncio da venda da Casa da Moeda) desnudam a necessidade de que o Brasil se integre completamente à ordem capitalista contemporânea sob a dominância do capital portador de juros.

Ao longo deste artigo, debateremos os termos desse ajuste austericida e integração subordinada do Estado brasileiro à ordem contemporânea, a partir das considerações de Bravo, Pelaez e Pinheiro (2018), no que se refere à política de saúde, aprofundando algumas questões que nos chamaram mais atenção, como as particularidades desse processo e como vem se explicitando a inviabilização do SUS e sua contrarreforma.

\section{PARTICULARIDADES DA CONTRARREFORMA NA POLÍTICA DE SAÚDE E O DES- MONTE DO SUS NO GOVERNO TEMER}

Concordamos com Bravo, Pelaez e Pinheiro (2018) ao afirmar que o processo de contrarreforma na política de saúde vem se dando desde os anos 1990, de forma sistemática no Brasil nos governos Fernando Henrique Cardoso (FHC), passando pelos governos do Partido dos Trabalhadores e até o tempo presente. Porém, mesmo que esse processo seja continuidade desde então, cada governo imprimiu suas particularidades. Até o governo Dilma Roussef, uma estratégia comum a todos eles era a não explicitação da contrarreforma na saúde, apresentando-se nos governos FHC como necessidade de aperfeiçoamento da gestão, mas não se posicionando abertamente contra os princípios do Sistema Único de Saúde (SUS); seja nos governos do Partido dos Trabalhadores (PT), como uma modernização da reforma sanitária, com a necessidade de introdução de novas formas de gestão, abrindo ainda mais espaço para o capital da saúde dentro e fora do SUS.

Assim, a contrarreforma na política de saúde não ocorreu “[...] na forma de um movimento explícito e amplo. Para burlar as possíveis resistências, se constituiu de modo fragmentado, experimental e se espraiando paulatina e continuadamente no interior do sistema" (SOARES, 2010, p. 56). Tanto nos governos FHC, quanto Lula da Silva e Dilma Roussef, esses termos já foram bem debatidos por Costa (2000), Rizzotto (2000), Soares (2010). No governo Lula da Silva consolida-se uma importante estratégia da contrarreforma na saúde: a refuncionalização dos princípios do SUS.

Os princípios do SUS não são negados explicitamente, tendo em vista as possibilidades de resistência. Os princípios e fundamentos legais do SUS são refuncionalizados, adquirem conteúdos distintos da racionalidade hegemônica no projeto de reforma sanitária, incorporando elementos da nova racionalidade hegemônica [...] (SOARES, 2010, p. 56).

Argum., Vitória, v. 10, n.1, p. 24-32, jan./abr. 2018. 
Diante da necessidade de flexibilixar os princípios da reforma sanitária, acentua-se uma outra tendência da contrarreforma da saúde nos governos do PT: a configuração de um terceiro projeto em disputa no âmbito da política, que denominamos Projeto SUS Possível.

[...] fragmentos descolados da totalidade do projeto de Reforma Sanitária são recuperados, o que revela não só as limitações dessa incorporação no sentido de reatualização ou modernização da Reforma Sanitária - como é apresentada - mas também expressa um caráter diverso e, muitas vezes, contrário ao sentido original, como é o caso da gestão pública segundo o marco legal original do SUS e as propostas de gestão de âmbito privado (SOARES, 2010, p. 59-6o).

Todavia, com o decurso do golpe e do governo Temer, a contrarreforma do Estado brasileiro e precisamente da política de saúde entra em uma nova fase de explicitação do processo. Ainda em suas declarações iniciais, o Ministro da Saúde Ricardo Barros afirma abertamente à imprensa a necessidade de rever o tamanho do SUS. Tal estratégia é reveladora da direção das alterações impetradas pelo governo Temer e, ao mesmo tempo, do momento do Estado brasileiro e seus vínculos com o capital nacional e internacional. A não preocupação em dissimular a ofensiva contra o SUS e a reforma sanitária expressa, de fato, o aviltamento da cultura crise, conforme a discussão de Mota (1995), recuperada por Bravo, Pelaez e Pinheiro (2018).

Mota (2017) afirma que o conjunto dessa ofensiva vem se caracterizando como uma grande regressão civilizatória nos marcos da sociedade brasileira, configurando-se o que Marx denominou de expropriação da classe trabalhadora, precisamente sobre os direitos e as políticas sociais. Essa expropriação no âmbito do direito à saúde e da política de saúde atinge seu ápice a partir das alterações e proposições discutidas por Bravo, Pelaez e Pinheiro (2018): a aprovação da Emenda Constitucional 95, que institui o congelamento do teto dos gastos primários, impondo sobre o orçamento da saúde uma restrição que pode chegar a 640 bilhões, segundo estudo do IPEA (VIEIRA; BENEVIDES, 2016); a proposição dos Planos Populares de Saúde que está em vias de ser regulamentada; a proposição de alteração na lei que regulamenta os planos de saúde no Brasil, a alteração na Política Nacional de Atenção Básica em Saúde e as alterações na política de saúde mental, precisamente na Rede de Atenção Psicossocial, que retrocede em aspectos fundamentais à reforma psiquiátrica.

De forma pertinente Bravo, Pelaez e Pinheiro (2018) destacam que uma das características do governo Temer é sua "[...] articulação efetiva com o setor empresarial de saúde” (BRAVO; PELAEZ; PINHEIRO, 2018, p. 16). De fato, evidencia-se uma profunda instrumentalização do Estado brasileiro em favor dos interesses do capital da saúde, sem qualquer preocupação em atender os interesses da classe trabalhadora. O compromisso explícito do governo nessa fase da contrarreforma da saúde é com as grandes corporações econômicas privadas da saúde, anunciado desde antes da nomeação do Ministro:

- o então deputado federal Ricardo Barros reuniu-se com a elite médica paulista no Hospital Sírio Libanês, a fim de ter seu nome legitimado por esse grupo;

- ademais, o próprio ministro não tinha qualquer experiência com a gestão da política de saúde, seu contato com o setor era o fato do "[...] seu maior doador individual de campanha ser Elon Gomes de Almeida, presidente do Grupo Aliança, administradora de benefícios de saúde" (TRUFFI, 2016, não paginado). - em diversas declarações o ministro afirmou o seu

Argum., Vitória, v. 10, n.1, p. 24-32, jan./abr. 2018. 
compromisso com o capital privado da saúde ao informar "[...] sou o ministro da saúde, não sou o ministro do SUS” (CANCIAN, 2016, não paginado).

Assim, expressa-se um completo descompromisso com a saúde pública segundo os interesses dos trabalhadores e uma indisfarçada instrumentalização da gestão do Ministério da Saúde pelos interesses do capital privado da saúde e seus representantes.

Aqui é importante destacar que o mercado privado da saúde, particularmente dos planos e operadoras de saúde, perdeu 3,1 milhões de usuários nos três últimos anos (CASEMIRO, 2018). Daí a necessidade de ampliação do mercado via institucionalização dos planos populares de saúde. Todavia, apesar da queda no número de usuários, o setor, em 2016, registrou um aumento de receita em $12 \%$ e de lucro líquido da ordem de $66 \%$, segundo dados da ANS (CASEMIRO; CAVALCANTI, 2017). A estratégia das operadoras foi repassar a conta para o consumidor, principalmente o de contratos coletivos que chegaram a até $40 \%$. Ademais, a própria ANS estipulou nos últimos 3 anos (2015-2016-2017) os maiores ajustes desde a sua criação, ficando em torno de $13,55 \%$, bem acima da inflação, garantindo maior rentabilidade para o setor (AGÊNCIA NACIONAL DE SAÚDE SUPLEMENTAR, [2018?]).

Uma outra expressão do que podemos denominar de captura e profunda instrumentalização do espaço público pela lógica privada na gestão Temer é o contexto favorável ao lançamento do documento Coalizão Saúde Brasil: uma agenda para transformar o sistema de saúde, em 2017 (COALIZÃO..., 2017). Segundo Bravo, Pelaez e Pinheiro (2018), o grupo Coalizão Saúde surge em 2014, mas é em 2016, no contexto do golpe institucional, que passa a agregar 24 entidades articuladoras do capital da saúde: desde indústrias como a Jonhson\&Johnson, passando por entidades de operadoras de planos de saúde, indústria farmacêutica, associação de hospitais privados, confederação dos hospitais e entidades filantrópicas. Chama a atenção nas proposições do grupo a defesa clara de uma ampliação da "[...] participação dos prestadores privados de assistência à saúde na definição da política de saúde [...]” (BRAVO; PELAEZ; PINHEIRO, 2018, p. 17) e para isso a necessidade da criação de conselhos de especialistas "[...] ligados diretamente aos gabinetes dos prefeitos" (BRAVO; PELAEZ; PINHEIRO, 2018, p. 17).

Na prática, a gestão do ministro Ricardo Barros trabalhou em sintonia com essas proposições, pois mantinha contato permanente com setores e entidades privadas da saúde, como se fossem efetivamente conselhos consultivos orientadores da gestão da política. Desde sua reunião inicial no Hospital Sírio Libanês, em São Paulo, o referido Ministro permaneceu articulado com essa entidade e segmentos do setor. Saiu, inclusive, dessa reunião com a proposta de criação de um grupo no aplicativo What's App "[...] para discutir medidas a serem tomadas durante seu mandato. O cardiologista Roberto Kalil, o cirurgião Fabio Jatene, o oncologista Paulo Hoff, o cirurgião Paulo Chapchap, o infectologista David Uip, do Hospital Sírio-Libanês, e Claudio Lottenberg, do Hospital Albert Einstein, estavam entre os nomes do grupo" (LOPES, 2016, não paginado). Ademais, comprometeu-se a mensalmente de se reunir em São Paulo com médicos para discutir sua agenda política (LOPES, 2016).

Assim, para além do profundo aprisionamento da gestão pública pelos interesses privados, a gestão do governo Temer na política de saúde mostra-se completamente antagônica ao projeto de Reforma Sanitária, ferindo de morte seus princípios basilares, principalmente três:

Argum., Vitória, v. 10, n.1, p. 24-32, jan./abr. 2018. 
- a universalidade do acesso à saúde: quando impõe uma restrição orçamentária por 20 anos, o governo Temer coloca em patamares jamais vistos o subfinanciamento do SUS num momento de aumento da demanda do sistema; quando abre espaço para a regulamentação de planos populares e defende abertamente a desoneração do SUS via oneração dos usuários no consumo de planos privados; ao fazê-lo, segue a risca os fundamentos dos documentos Ponte para o Futuro (FUNDAÇÃO ULLYSSES GUIMARÃES, 2015) e Travessia Social (FUNDAÇÃO ULLYSSES GUIMARÃES, [2016]), como bem apontado por Bravo, Pelaez e Pinheiro (2018). Em verdade, tais ações engendrarão um processo de focalização da política a níveis extremos, inviabilizando, por completo, um SUS para todos.

- a publicidade do direito à saúde: massifica-se nos argumentos e proposições do Ministério da Saúde a ideia de que todos devem colaborar diante do colapso do financiamento do sistema. Na prática, a colaboração se daria via aquisição de um plano popular ou até mesmo a compra de um serviço de saúde numa clínica popular - como também vem sendo muito veiculado na grande mídia. Apesar da resistência do movimento sanitário, a população usuária do SUS tem se mobilizado pouco em defesa do direito público à saúde, evidenciando que o conteúdo de negação do direito e reprodução da ideia de inviabilidade do SUS, vem se colocando na ordem do dia pelos setores privados. Assim, de fato, a destruição da concepção do direito público à saúde chega ao seu ápice.

- a participação social: o controle social que, nos governos anteriores, já havia sofrido duros golpes num contínuo processo de desvalorização e marginalização em relação às grandes decisões da política de saúde - como a introdução das novas modalidades de gestão - passa a ser completamente alijado dos processos decisórios, vê-se o exemplo da aprovação da nova PNAB circunscrita à Comissão Intergestora Tripartite e sem debate com a sociedade. Concomitantemente, uma supervalorização dos espaços e grupos formados por representantes e consultores do capital privado da saúde, os denominados especialistas. Esquece-se, no entanto, de informar que são especialistas em saúde privada e mercantilização do direito à saúde.

Vive-se no Brasil um momento crucial da ofensiva capitalista no decurso do golpe institucional. Tal ofensiva só encontra terreno fértil para sua realização mediante a inviabilização ou profunda restrição das alternativas civilizatórias e democráticas, mesmo sob a ordem capitalista. A prisão do ex-presidente Lula da Silva, assim, constitui-se elemento importante nesse processo:

O programa do golpe precisa seguir sendo aplicado, porém, por meio de um governo respaldado pelas urnas [...]. A burguesia não só considera Lula incapaz de aplicar tal programa nos moldes exigidos por ela, como não encontra nenhum candidato confiável capaz de seguramente derrotar o petista nas urnas. Numa era de desagregação social sem precedentes e de contrarreformas pletóricas, a preservação do regime do sufrágio universal parece só ser possível, para a burguesia, se o próprio sufrágio universal for maculado ou cassado, e se a eleição não for apenas uma contrafação. É isto o que explica, fundamentalmente, a condenação de Lula e sua prisão, decretada hoje pelo juiz Sérgio Moro [...]. O Lula que será preso nos próximos instantes não é o Lula que se afastou de um projeto emancipatório da classe trabalhadora, mas sim aquele que se dispõe a tentar de novo oferecer três refeições diárias para ela dentro do capitalismo (DEMIER, 2018, p. 1).

Argum., Vitória, v. 10, n.1, p. 24-32, jan./abr. 2018. 
Não é simples coincidência que na mesma semana da prisão do ex-presidente, a recémcriada Federação Brasileira de Planos de Saúde (FEBRAPLAN) divulgue a organização do $\mathbf{1}^{\mathbf{o}}$ Fórum Brasil, sob o lema: participe do fórum que iniciará a construção de um novo Sistema Nacional de Saúde. Ademais, de forma concomitante, no dia da referida prisão, a Revista Veja publica matéria assinada por Cutait e Medici (2018), intitulada Pela reforma do SUS.

Vimos que o processo de contrarreforma vem se dando desde os anos 1990 e com ele a desconstrução da concepção de direito público. Mota (1995) afirma que a mediação deixa de ser a cidadania de direito ou o direito público e passa a ser a cidadania de consumo. No entanto, tal processo se dava num espaço de disputa acirrado e, sem dúvida, que no campo do direito à saúde, com a mobilização do movimento sanitário e a historicidade de apropriação da compreensão da saúde como direito público, havia um tensionamento maior que possibilitou barrar uma contrarreforma ainda mais ofensiva em governos anteriores - como foi o exemplo da tentativa de aprovação de projeto de lei que regulamentava as fundações estatais de direito privado, na gestão Lula da Silva, bem como da audiência da operadora de plano de saúde Amil, que se reuniu com a então presidente Dilma Roussef, a fim de defender a implementação dos planos populares de saúde. Em ambos os casos, o movimento sanitário conseguiu barrar o trâmite do processo.

De fato, no governo Temer, a defesa explícita de uma reforma do SUS e de sua inviabilidade nos anuncia que a descontrução da concepção de direito público na saúde está andando a passos largos, agora alimentada por uma cultura da crise que anuncia a quebra do Estado em decorrência dos gastos com políticas sociais consideradas de cunho populista1. Sem dúvida alguma que a inviabilização e/ou profunda restrição de alternativas emancipatórias - mesmo que sob os limites da cidadania burguesa - constitui-se o esteio para o aprofundamento da espoliação de bens e direitos públicos, precisamente o direito à saúde.

\section{Considerações Finais}

Estamos assistindo, segundo Mota (2017), a uma regressão civilizatória e a expropriação de direitos e políticas sociais com o objetivo de atualizar as necessidades de reprodução do capitalismo. A apropriação do fundo público, particularmente do fundo público da saúde, torna-se objeto de desejo dos grandes e pequenos conglomerados econômicos da saúde, inclusive internacionais - desde operadoras de planos de saúde, indústria farmacêutica, rede de farmácias, rede de hospitais, etc.

O conjunto de proposições e alterações na política de saúde do governo Temer configuram a maior e mais grave ofensiva sofrida pela reforma sanitária brasileira desde a Constituição de 1988. As medidas discutidas em Bravo, Pelaez e Pinheiro (2018) denunciam o caráter profundamente regressivo da aprovação do teto de gastos por 20 anos, da reformulação da PNAB e desestruturação da Estratégia Saúde da Família, dos planos populares de saúde, das alterações na Rede de Atenção Psicossocial (RAPS) da Política de Saúde Mental e da proposta de alteração na regulamentação dos planos de saúde.

\footnotetext{
${ }^{1}$ Forma como o então Ministro da Fazenda do Governo Temer, Henrique Meireles, se refere às políticas sociais nos governos do PT.
}

Argum., Vitória, v. 10, n.1, p. 24-32, jan./abr. 2018. 
Ademais, a gestão do Ministério da Saúde vem atuando como fiel representante dos setores empresariais da saúde, nos seus mais diversos espaços, não só em contínua interlocução, mas possibilitando também uma maior articulação do capital da saúde, com aglutinação de entidades, elaboração de documentos, realização de fóruns, etc., com a finalidade de influenciar diretamente na condução da política. Observa-se, assim, uma instrumentalização contumaz do Estado pelos interesses do capital na área da saúde.

Nessa fase da contrarreforma, evidencia-se não só o abandono por completo da concepção de reforma sanitária, mas o abandono do próprio SUS, anunciando-se a sua inviabilidade e a necessidade de sua reformulação.

O SUS, todavia, é um dos maiores patrimônios da classe trabalhadora brasileira, constitui-se também, espaço de luta e contradição, de disputa de projetos. Em tempos de ataques à democracia e ao direito público à saúde, num contexto de golpe institucional e autoritarismo, torna-se imprescindível a organização e mobilização na defesa do projeto de reforma sanitária, conforme ressaltado por Bravo, Pelaez e Pinheiro (2018). Assim, devemos nos apropriar dos fundamentos do projeto de reforma sanitária e também da sua perspectiva emancipatória na defesa da democratização da sociedade, do Estado e da política de saúde, sem perder de vista também o seu conteúdo revolucionário.

\section{Referências}

BRASIL. Ministério da Saúde. Política Nacional de Atenção Básica. Brasília, 2017.

\section{AGÊNCIA NACIONAL DE SAÚDE SUPLEMENTAR. Histórico de reajuste por variação}

pessoa física. Brasília (DF), [2018]. Disponível em: <http://www.ans.gov.br/planos-desaude-e-operadoras/espaco-do-consumidor/reajustes-de-precos-de-planos-desaude/historico-de-reajuste-por-variacao-de-custo-pessoa-fisica>. Acesso em: 7 abr. 2018.

\section{VIEIRA, F. S.; BENEVIDES, R. P. de S. e. Os impactos do novo regime} fiscal para o financiamento do Sistema Único de Saúde e para a efetivação do direito à saúde no Brasil. Brasília (DF): Instituto de Pesquisa Econômica Aplicada, 2016. (Nota técnica, n. 28). Disponível em:

$<$ http://www.ipea.gov.br/portal/index.php?option=com_content\&id=28589 $>$. Acesso em: 7 abr. 2018.

BRAVO, M. I.; PELAEZ, E.; PINHEIRO, W. As contrarreformas na política de saúde do governo Temer. Argumentum, Vitória, v. 10, n. 1, p. 9-23, jan./abr.2018.

BRAZ, M. O golpe nas ilusões democráticas e a ascensão do conservadorismo reacionário. Serviço Social e Sociedade, São Paulo, n. 128, p. 85-103, jan./abr. 2017.

CANCIAN, N. Ministro da saúde defende "plano popular de saúde" para aliviar o SUS. In Folha de São Paulo, São Paulo, 6 jul. 2016. Disponível em <http://www1.folha.uol.com.br/cotidiano/2016/o7/1789101-ministro-da-saude-defendeplano-de-saude-mais-popular-para-aliviar-o-sus.shtml>. Acesso em: 7 abr. 2018.

Argum., Vitória, v. 10, n.1, p. 24-32, jan./abr. 2018. 
CASEMIRO, L.; CAVALCANTI, G. Operadoras de plano de saúde ampliam receita, apesar de perda de clientes. O Globo, São Paulo, 2 jul. 2017. Disponível em:

<https://oglobo.globo.com/economia/operadoras-de-plano-de-saude-ampliam-receitaapesar-de-perda-de-clientes-21544177>. Acesso em: 7 abr. 2018.

CASEMIRO, L. Planos de saúde perdem mais de 3 milhões de usuários nos últimos 3 anos. O Globo, São Paulo, 25 jan. 2018. Disponível em:

<https://oglobo.globo.com/economia/planos-de-saude-perdem-mais-de-3-milhoes-deusuarios-em-3-anos-22326983>. Acesso em: 7 abr. 2018.

COALIZÃO SAÚDE BRASIL. Coalizão Saúde Brasil: uma agenda para transformar o sistema de saúde. São Paulo, 2017.

COSTA, N. R. Reforma do Estado e o setor saúde: a experiência brasileira da última década. In: CONFERÊNCIA NACIONAL DE SAÚDE, 20oo. Brasília (DF), 20oo. (Caderno, n. 11).

CUTAIT, R.; MEDICI, A. “Pela reforma do SUS”. Revista Veja, São Paulo, 7 abr. 2018. Disponível em: <https://veja.abril.com.br/revista-veja/pela-reforma-do-sus/>. Acesso em: 7 abr. 2018.

DEMIER. F. Os sentidos de uma prisão: Lula, democracia e as pessoas na sala de jantar. Esquerda Online, São Paulo, 6 abr. 2018. Disponível em:

<https://esquerdaonline.com.br/2018/o4/o6/os-sentidos-de-uma-prisao-lula-democracia-eas-pessoas-na-sala-de-jantar/>. Acesso em: 7 abr. 2018.

FUNDAÇÃO ULLYSSES GUIMARÃES. Travessia Social. Brasília (DF), [2016]. Disponível em: <https://www.fundacaoulysses.org.br/blog/acervo/>. Acesso em: 7 abr. 2018.

FUNDAÇÃO ULLYSSES GUIMARÃES. Ponte para o Futuro. Brasília (DF), 2015. Disponível em: <https://www.fundacaoulysses.org.br/blog/acervo/>. Acesso em: 7 abr. 2018.

HARVEY, D. O novo imperialismo. São Paulo: Loyola, 2005.

JINKINGS, I.; DORIA, K.; CLETO, M. Por que gritamos golpe?. São Paulo: Boitempo, 2016.

KLIASS, P. Austericídio e outras maldades: não tendo sido eleito para o imenso estrago que está promovendo, o governo parece estar preocupado apenas em cumprir com o mandato recebido do financismo. Carta Maior, São Paulo, 23 mar. 2017. Disponível em: $<$ https://www.cartamaior.com.br/?/Editoria/Economia/Austericidio-e-outrasmaldades/7/3788o >. Acesso em: 31 mar. 2018.

LOPES, A. D. Novo Ministro da Saúde já tem compromisso marcado. Revista Veja, São Paulo, 24 maio 2016. Disponível em: <https://veja.abril.com.br/saude/novo-ministro-dasaude-ja-tem-compromisso-marcado/>. Acesso em: 7 abr. 2018. 
MARQUES, R. M.; UGINO, C. M. O Brasil é chamado à ordem. Argumentum, Vitória, v. 9, n. 3, p. 8-23, set./dez. 2017.

MOTA, A. E. Cultura da crise e seguridade social: um estudo sobre as tendências da previdência e da assistência social brasileira nos anos 80 e 9o. 2. ed. São Paulo: Cortez, 1995.

MOTA, A. E. A regressão civilizatória e as expropriações de direitos e das políticas sociais. Argumentum, Vitória, v. 9, n. 3, p. 30-36, set./dez. 2017.

RIZZOTTO, M. L. F. 2000. 267 f. O Banco Mundial e as políticas de saúde nos anos 90. (Tese de Doutorado)-Pós-Graduação da Faculdade de Ciências Médicas da Universidade Estadual de Campinas, Campinas, 2000.

SOARES, R. C. Contrarreforma na política de saúde e prática profissional do Serviço Social nos anos 200o. In: MOTA, Ana E. (Org.). As Ideologias da contrarreforma e o Serviço Social. Recife: UFPE, 2010.

TRUFFI, R. R. B. O ministro dos planos de saúde. Carta Capital, São Paulo, 5 set. 2016. Disponível em: <https://www.cartacapital.com.br/revista/916/ricardo-barros-o-ministro-dosplanos-de-saude>. Acesso em: 7 abr. 2018.

\footnotetext{
Raquel Cavalcante SOARES

Mestre em Serviço Social pela Universidade Federal de Pernambuco (200o). Doutora em Serviço Social pela Universidade Federal de Pernambuco (2010). Professora Adjunto IV da Universidade Federal de Pernambuco no Departamento de Serviço Social. Coordenadora do projeto de pesquisa "Contrarreforma na política de saúde: privatização e superprecarização". Trabalha principalmente com os seguintes temas: contrarreforma na política de saúde, Serviço Social na saúde.
} 